\title{
1 Selection in response to community diversity alters plant performance and
}

\section{2 functional traits}

3 Sofia J. van Moorsel*, Marc W. Schmid, Terhi Hahl, Debra Zuppinger-Dingley and Bernhard

4 Schmid $^{*}$

5

6 Department of Evolutionary Biology and Environmental Studies, University of Zurich,

7 Winterthurerstrasse 190, CH-8057, Switzerland

$8 \quad{ }^{*}$ Corresponding authors.

9

10 Email addresses:

11 sofia.vanmoorsel@ieu.uzh.ch

12 contact@mwschmid.ch

13 terhi.hahl@ieu.uzh.ch

14 debra.zuppinger@ieu.uzh.ch

15 bernhard.schmid@ieu.uzh.ch

16

17 Type of contribution: Original research article

18

19 Keywords:

20 Biodiversity effects, Grassland, Plant productivity, Selection, Trait variation

21 Article information:

225107 words (main text excl. references and figure captions), 7 figures, 2 tables 


\section{ABSTRACT}

25 In grassland biodiversity experiments the positive biodiversity-ecosystem functioning

26 relationship generally increases over time. However, we know little about the underlying

27 short-term evolutionary processes. Using five plant species selected for twelve years in a

28 biodiversity experiment in mixture or monoculture and plants without such a selection

29 history, we assessed whether differential selection altered productivity, biodiversity effects,

30 and functional trait differences within newly assembled monocultures and 2-species

31 mixtures. Plants without past community selection history produced the lowest assemblage

32 biomass and showed the weakest biodiversity effects. In newly assembled mixtures, plants

33 with a selection history in mixtures produced more biomass than plants with a monoculture

34 selection history. Biodiversity effects were generally positive and differed significantly

35 between selection histories. However, contrary to our expectations, biodiversity effects were

36 not stronger for mixture-type plants. Biodiversity effects were influenced by both trait

37 differences between plants and community-weighted means, but these relationships were

38 mostly independent of selection history. Our findings suggest that twelve years of selection

39 history in monocultures or species mixtures differentiated plants of each species into

40 monoculture- and mixture-types. Such rapid evolution of different community-types within

41 grassland species and its effect on ecosystem services and functioning are likely to be

42 important for species conservation practice.

43 


\section{Introduction}

The importance of biodiversity for maintaining ecosystem functions such as productivity or nutrient cycling is now well established (Cardinale et al., 2012). The biodiversity-productivity relationship is positive in grassland ecosystems (e.g. Isbell et al., 2011; Tilman et al., 2001), with biodiversity increasing multiple ecosystem functions (Soliveres et al., 2016). The positive effect of biodiversity strengthens with time (Cardinale et al., 2007; Reich et al., 2012), suggesting that complementarity between the co-occurring species can increase over time (Fargione et al., 2007).

Despite more than a decade of research on the biodiversity-productivity relationship (e.g. Reich et al., 2012), we know little about the evolutionary mechanisms that potentially affect species interactions (Thorpe et al., 2011). Selection acting on traits may increase ecological combining ability (Aarssen, 1983; Harper, 1977) via niche differentiation in plant mixtures (Zuppinger-Dingley et al., 2014). Such adaptation occurs when there is either sufficient standing genetic variation in a population and a sorting out of the most suitable genotypes (Fakheran et al., 2010) or by recombination and novel mutations (Anderson et al., 2011). Furthermore, plants may adapt to a novel environment by phenotypic plasticity (Price et al., 2003; Turcotte and Levine, 2016), thus changing their morphology without genotypic changes. Epigenetic variation may contribute to phenotypic variation and thus provides a further source for selection and adaptation (Bossdorf et al., 2008).

Whereas the influence of environmental factors on adaptive responses of plant populations is well studied (e.g., Joshi et al., 2001; Schmid, 1985), much less effort has been devoted to studying the influence of community diversity on a species' performance (but see Kleynhans et al., 2016; Lipowsky et al., 2011). Based on previous observations in experimental ecosystems suggesting a "division of labor" among species in plant mixtures, it is likely that community diversity plays a role in the evolution of plant functional trait 
variation. For example, in forests more diverse tree communities express greater crown complementarity (Niklaus et al., 2017; Williams et al., 2017). In diverse grassland communities increased complementarity effects, as estimated by the additive partitioning method of Loreau and Hector (2001), promote community productivity via diversification of the canopy structure and hence light and space use (Allan et al., 2011; Spehn et al., 2000), soil resource partitioning (Fornara and Tilman, 2008; Roscher et al., 2008; von Felten et al., 2009), root depth distribution (Mueller et al., 2013) and distribution of leaf mass (Wacker et al., 2009). However, these in situ observations do not allow separating the contribution of phenotypic plasticity from potential underlying shifts in the population structure due to selection of different community-types. To understand to which extent evolutionary processes drive these differences, it is thus important to assess biodiversity effects in a common environment.

Using the additive partitioning method (Loreau and Hector, 2001), the net biodiversity effect (NE) can be partitioned into complementarity (CE) and sampling effects (SE). When the CE drives over-yielding, most species are expected to contribute to higher productivity in more diverse communities. In contrast, when the SE drives over-yielding, a few dominant species increase community productivity in species mixtures. The CE is therefore related to coexistence and trait variation between species as it inherently suggests a differentiation in functional traits (Cadotte et al., 2009; Flynn et al., 2011). Conversely, the SE should be driven by traits of the dominant species and thus by community-weighted trait means (CWMs); an increase in CWMs (e.g., taller plants) should increase biodiversity effects (Cadotte, 2017; Roscher et al., 2012).

The use of functional traits to define species' niches has a long history in evolutionary ecology (Roughgarden, 1974; Schoener and Gorman, 1968; van Valen, 1965). Recently it has become a popular approach in functional ecology (Violle et al., 2007) to 
94 explain mechanisms of species coexistence and ecosystem functioning (Hart et al., 2016;

95 Kraft et al., 2015). However, we do not know how such trait-based niches and the associated

96 functional traits may evolve (Roscher et al., 2015; Sterck et al., 2011).

97 We tested whether community diversity can act as a selective environment shaping

98 biodiversity effects and functional traits. To test for the heritability of these effects and traits,

99 we grew offspring of plants grown for twelve years in a biodiversity experiment in

100 monocultures and two-species mixtures in a common environment. We measured biomass

101 production and traits of individual plants in monocultures and mixtures established with

102 seedlings from either a selection history of experimental monoculture or mixture

103 communities in a biodiversity field experiment (Jena Experiment, see Roscher et al., (2004)

104 for details) or in monoculture fields from the commercial seed supplier which provided the

105 original seeds for the Jena Experiment in 2002. We refer to the plants growing in Jena since

1062002 in mixture or monoculture as mixture- and monoculture-type plants, respectively. The

107 plants derived from seeds obtained from the commercial supplier in 2014 are referred to as 108 naïve plants.

109 We previously assessed selection outcomes in the Jena Experiment after eight years

110 and one controlled sexual reproduction cycle (Zuppinger-Dingley et al., 2014). Here, we

111 prolonged the selection treatment by four more years, added a second controlled sexual

112 reproduction cycle, and refined our insights by measuring all individuals in test communities,

113 thus also allowing us to assess intra-specific variation within communities. We included

114 naïve plants as a control treatment without selection. We hypothesized that during the twelve

115 years of selection in the experimental field, mixture-type plants may have evolved increased

116 mixture performance. In turn, this may be associated with a larger NE, in particular CE, and

117 larger between-species trait variations. Conversely, we expected monoculture-type plants to

118 have evolved increased monoculture performance, which should be related to larger within- 
species trait variation.

120

\section{Materials and methods}

\subsection{Plant selection histories}

123

To test whether plant types selected over twelve years in mixtures outperform those

124 types selected in monocultures when assembled in mixture test communities, we chose five 125 species grown in monoculture and mixture plots in the Jena Experiment (Jena, Thuringia,

126 Germany, $51^{\circ} \mathrm{N}, 11^{\circ} \mathrm{E}, 135 \mathrm{~m}$ a.s.l., see Roscher et al., (2004) for experimental details):

Plantago lanceolata L., Prunella vulgaris L., Veronica chamaedrys L., Galium mollugo L.

135 year in spring, summer and autumn and by mowing twice per year at peak biomass in spring 136 and summer.

137 We used plant progeny from three different selection histories for the experiment.

138 Plants without selection history in the Jena Experiment (selection history "naïve") were 139 obtained from a commercial seed supplier (Rieger Hoffmann GmbH, Blaufelden- 
142

143

144

145

146

147

148

149

150

151

152

153

154

155

156

157

158

159

160

161

162

163

164

165

166

\subsection{First controlled seed production}

In spring 2010, plant communities of 48 plots (12 monocultures, 12 two-species

mixtures, 12 four-species mixtures and 12 eight-species mixtures) of the Jena Experiment (Roscher et al., 2004) were collected as cuttings and transplanted into an experimental garden in slug-exclosure compartments at the University of Zurich, Switzerland Switzerland $\left(47^{\circ} 33^{\prime} \mathrm{N},{ }^{\circ} 37^{\prime} \mathrm{E}, 534 \mathrm{~m}\right.$ a.s.1.), in the identical plant composition as the original experimental plots for the first controlled sexual reproduction among co-selected plants (ZuppingerDingley et al., 2014). In spring 2011, the seedlings produced from the seeds of the first controlled sexual reproduction in Zurich were transplanted back into those plots of the Jena Experiment from where the parents had originally been collected. In these newly established plots, plant communities with an identical composition to the original communities were maintained for three years until 2014.

\subsection{Second controlled seed production}

To ensure a second sexual reproductive event for the collection of seed material, entire plant communities from the experimental plots replanted in Jena in 2011 were excavated in March 2014. As for the first controlled seed production, the plants from Jena were used to establish plots with an identical plant composition in the experimental garden at the University of Zurich,. We added a $30 \mathrm{~cm}$ layer of soil (1:1 mixture of garden compost and field soil, pH 7.4, commercial name Gartenhumus, RICOTER Erdaufbereitung AG, Aarberg, Switzerland), to each plot to ensure the plants established well. Mesh fabric netting around each plot minimized the possibility of cross-pollination between the same species from different experimental plots. We collected seeds from seven monoculture plots, one 4species mixture plot and six 8-species mixture plots in the experimental garden. We did not include seeds from 2-species mixtures as we expected that the community diversity selection 
167 pressure may not be different enough from monocultures. Seeds from different mother plants

168 were pooled together and cleaned manually for three species and mechanically for two 169 species ( $P$. lanceolata and $P$. vulgaris). The dry seeds were stored for 5 months at $5^{\circ} \mathrm{C}$ for 170 cold stratification.

171

$172 \quad 2.4$ Experimental set up

173 All seeds were germinated in germination soil (“Anzuchterde", Ökohum,

174 Herbertingen, Germany) under constant conditions in the glasshouse without additional light

175 in December 2014. From 25 February to 13 March 2015, seedlings were planted in

176 monocultures of four individuals or 2-species mixtures of two plus two individuals into pots

177 (two liters) filled with neutral agricultural soil (50\% agricultural sugar beet soil, 25\% perlite,

$17825 \%$ sand; Ricoter AG, Aarberg, Switzerland). At the beginning of the experiment the

179 studied plants were infested by fungus gnats (Bradysia spp.), which caused seedling

180 mortality during the experiment. Seedlings that died in the first two weeks were replaced

181 with seedlings of the same species and age.

We planted species assemblages in six blocks (replicates); each block included the full

183 experimental design. Species pairs were chosen according to seedling availability. The full

184 design (every possible species combination) was intended but could not be realized due to

185 seedling mortality and low germination rates for some species (e.g. G. mollugo). Within each

186 block, pots were placed on three different tables in the glasshouse in a randomized fashion

187 without reference to selection history or assembly treatment. During the timeframe of the

188 experiment we did not move pots but noted their position in the glasshouse. Single pots

189 always contained four plants of the same selection history. Each selection history $\times$ species

190 assembly combination was replicated five to six times depending on plant availability. We

191 planted 30 monoculture and 42 mixture assemblages with mixture selection history, 30 
192 monoculture and 60 mixture assemblages with monoculture selection history and 24

193 monoculture and 35 mixture assemblages with naïve selection history, a total of 221 pots and

194884 plants (Appendix S2 for monoculture identities and species combinations).

195 During the experiment, the plants were initially kept at day temperatures of $17-20^{\circ} \mathrm{C}$

196 and night temperatures of $13-17^{\circ} \mathrm{C}$ without supplemental light. To compensate for

197 overheating in summer, an adiabatic cooling system (Airwatech; Bern, Switzerland) was

198 used to keep inside temperatures constant with outside air temperatures. The plants were not

199 fertilized. Due to an infestation of white flies (Trialeurodes vaporariorum, Westwood 1856)

200 and spider mites (Tetranychidae spp., Donnadieu 1875), we applied the insecticide

201 SanoPlant Neem (1\% Azadirachtin A (10 g/l); Maag AG) three times. The fungicide Fenicur

202 (Oleum foeniculi, Andermatt Biocontrol) against powdery mildew (Podosphaera spp.) was

203 applied twice. Plant height, leaf thickness, specific leaf area (SLA) and individual

204 aboveground biomass were measured after twelve weeks of the experiment from 18 May to 4

205 June 2015. Leaf thickness was measured for three representative leaves using a thickness

206 gauge. Specific leaf area (SLA) of up to 20 representative leaves (depending on the leaf size

207 of the species) of each species in a pot was measured by scanning fresh leaves with a Li-

2083100 Area Meter (Li-cor Inc., Lincoln, Nebraska, USA) immediately after harvest and

209 determining the mass of the same leaves after drying. Plant height and individual

210 aboveground biomass were measured a second time after 24 weeks from 18-25 August 2015

211 at the end of the experiment. All four individuals in a pot were sampled. Research assistants,

212 who were not informed of the specific experimental treatments, assisted in the regular

213 measurements and harvesting of plants at the end of the experiment. 
217

\subsection{Data analysis}

We calculated pot-wise aboveground community biomass (plant community production) as the sum of the biomass of the four individual plants. Because the first measure assessed growth and the second regrowth, the harvests were analyzed separately. Relative between-species differences (RDs, absolute difference between two species divided by the mean of the two) in plant height (first and second harvest), leaf thickness (first harvest) and SLA (first harvest) were calculated for mixture assemblages. Relative differences within species were calculated for both mixture and monoculture assemblages taking the relative difference between two individuals of the same species per pot. SLA outliers (> 99\% percentile) were replaced with a maximum value (the $99 \%$ percentile, $n=6$ ). Furthermore, we calculated community-weighted means (CWMs) and pot standard deviation (SDs) for the same traits (R package "FD", Laliberté and Legendre 2010; Laliberté et al., 2014). Pots with dead plant individuals were excluded from the calculation of community-weighted means, but were included for the other data analyses. Net biodiversity effects (NE) were calculated by comparing the 2 -species mixtures with the average monoculture and partitioned according to Loreau and Hector (2001) into complementary (CE) and sampling (selection) effects (SE). This partitioning approach allows assessing how CE and SE contribute to the NE (Loreau and Hector 2001). To avoid confusion with the term selection used for the selection-history treatment, we here use the term "sampling effect" for the SE (see Zuppinger-Dingley et al., 2014). Additive partitioning calculations were based on the difference between the observed yield of each species in the mixture and the monoculture yield for that species and selection history averaged across blocks. Absolute values of CE and SE were square root-transformed and the original signs put back on the transformed values for analysis (Loreau and Hector 2001). Differences in these measures between mixtures assembled from plants with monoculture selection history and mixtures assembled from plants with mixture selection 
242 history would suggest differential evolution of trait-based niches between species as a

243 potential mechanism underlying biodiversity effects.

244 All statistical analyses were done in R (Version 3.2.3, R Core team 2016). Mixed-

245 model analysis was done using the R-package asreml (VSNI international, 2016) and results

246 were assembled in ANOVA tables. Selection-history treatment (naïve, monoculture,

247 mixture), assembly treatment (monoculture vs. 2-species mixture assemblages), species

248 identity of monoculture assemblages and of mixture assemblages (in short "species

249 assembly") and interactions of these were fixed-effects terms in the model. Table (including

250 blocks) was a random-effects term in the model. CWMs, RDs, within-species differences

251 and SDs of plant height, SLA and leaf thickness were added as covariates to determine the

252 influence of these covariates on community biomass and biodiversity effects.

253

254 3. Results

2553.1 Plant selection history and community productivity

256 Assemblages consisting of plants with naïve selection history produced the lowest

257 community biomass at both harvests (Fig. 1; Table 1). At the second harvest, such higher

258 productivity of selected plants was stronger in 2-species mixtures than in monocultures (Fig.

259 1; Table 1). At the second harvest, mixture-type plant assemblages outperformed

260 monoculture-type plant assemblages and this effect was marginally more pronounced in the

261 2-species mixtures (Fig. 1; Table 1).

262 Species identity in monoculture or mixture assemblages strongly influenced

263 community productivity and, especially at the first harvest, the interaction terms with

264 selection history were significant (Table 1). For example, at the first harvest, mixture-type

265 plants performed better than monoculture-type plants in newly assembled monocultures of $P$.

266 vulgaris and in mixtures of G. mollugo and P. vulgaris (Fig. 1a). However, in the two 
267 mixtures with the small herbs $V$. chamaedrys and $P$. vulgaris and $P$. lanceolata and $P$.

268 vulgaris, monoculture-type plants performed better than mixture-type plants (see Fig. 1a).

\subsection{Plant selection history and biodiversity effects}

Overall, biodiversity effects were positive at both harvests (Fig. 2, Table 2).

272 Communities of naïve plants at the first harvest showed larger SEs and at the second harvest

273 showed smaller NEs and CEs than communities of selected plants.

274 At the first harvest, NEs, CEs and SEs were also larger for communities assembled

275 from monoculture-type plants than for communities assembled from mixture-type plants

276 (Fig. 2a, Table 2a). In contrast, at the second harvest NEs, CEs and SEs were non-

277 significantly larger for communities assembled from mixture-type plants for most species

278 assemblages (Fig. 2b; Table 2b). As with the results obtained for community productivity,

279 the influence of selection history on biodiversity effects also depended on the specific

280 species combination in mixture assemblages (Table 2). NEs were larger for mixture-type

281 plants for the combinations of G. mollugo with either P. vulgaris or P. lanceolata at the first

282 harvest (Fig. A2 in Supplementary material; Table 2). At the second harvest, NEs and CEs

283 were generally more similar between selection histories across different combinations and

284 variation between the specific community compositions was mainly due to different SEs.

285 The much larger NE for mixture-type plants in the combination G. mollugo $+P$. vulgaris

286 was an exception (Fig. A2). For both harvests communities which included the legume $L$.

287 pratensis or the small herb $P$. lanceolata showed positive biodiversity effects (Fig. A2). Four

288 species combinations shifted between harvests from stronger CEs for monoculture-type

289 plants to stronger biodiversity effects for mixture-type plants (Fig. A2). The G. mollugo + P.

290 vulgaris combination showed a consistently larger CE for mixture-type plants. At the second 
291 harvest the different species combinations varied strongly in SEs, but not in CEs (Table 2).

292 SEs were often larger for mixture- than for monoculture-type plants (Fig. 2).

293

\subsection{Plant selection history and within- and between-species trait variance}

Whereas interspecific differences in plant height were marginally larger in mixture-

type plants, interspecific differences in leaf thickness were larger in monoculture-type plants

at the first harvest (Fig. 3). Intraspecific differences in SLA were larger for monoculture-type

298 plants. Furthermore, pot-level SDs in monoculture or mixture assemblages were non-

significantly larger for assemblages with monoculture- than with mixture-type plants (left

\subsection{Relationship between biodiversity effects and trait variation}

At the first harvest, the NE was negatively correlated with the RD of plant height but mixture-type plants, but not for naïve plants (Fig. 4c). At the second harvest, NEs and SEs were significantly negatively correlated with the RD of plant height (Fig. 5). CEs were not influenced by interspecific variation in plant height.

\subsection{Relationship between biodiversity effects and trait means}


316 NE, driven by the CE, decreased with increasing SLA. Leaf thickness had a marginally

317 significant effect on SE, but the directionality depended on selection history. Plant height did

318 not have a significant effect on the biodiversity effects at the first harvest. However, the

319 interaction between trait means and selection history was significant for the relationship

320 between the CWM of plant height and the SE at the first harvest. Selection history was not

321 significant for the relationship between biodiversity effects and CWMs for the other two

322 traits. At the second harvest, CWM of plant height had a significantly positive effect on NE,

323 CE and SE (Fig. 7), the biodiversity effects were therefore stronger for taller plants.

324 However, in contrast to the first harvest, at the second harvest no effect of selection history

325 on the relationship between the CWM of plant height and the SE was observed (Fig. 7).

\section{4. Discussion}

\subsection{Influence of plant selection history on community productivity}

Plant community productivity may be influenced by selection for increased niche differentiation in plants grown for eight years in mixtures (mixture-type plants) compared community productivity than the same monocultures with mixture-type plants. For naïve

336 plants, we expected intermediate community productivity in both monocultures and 337 mixtures. 
341 biomass, especially in 2-species mixtures, in the pots in the glasshouse in Zurich.

342 Evolutionary processes in the field plots likely led to the increased performance of selected

343 plants, because these plants were grown for a longer time without re-sowing. In contrast, the

344 naïve plants were re-sown every year in the commercial propagation cultures, thereby "re-

345 setting" any local adaptation with every generation.

346 Within the selected plants, mixture-type plants produced higher community biomass

347 than monoculture-type plants in 2-species mixtures. But mixture-type plants also produced

348 more biomass than monoculture-type plants when grown in monoculture, which reduced

349 biodiversity effects. The generally lower performance of monoculture-type plants may have

350 been due to selection for increased defense against pathogens that are known to accumulate

351 in monocultures (Schnitzer et al., 2011). Increased resource allocation to defense

352 mechanisms would result in reduced allocation to growth (Coley et al., 1985; Herms and

353 Mattson, 1992). However, during the 24 weeks of growth in the experiment, species-specific

354 pathogens may not have been present, removing the need for increased defense. Such

355 species-specific pathogens might have needed more time to accumulate and to render

356 increased pathogen resistance advantageous.

357 Selection-history effects varied strongly among species in monocultures and among

358 species compositions in 2-species mixtures. These findings emphasized that such studies

359 should include multiple species but at the same time sufficient replication in monoculture

360 and their combinations in mixture. High replication can more easily be achieved in

361 experiments with one focal species (e.g. Kleynhans et al., 2016; Rottstock et al., 2017), but

362 extrapolating results from such experiments might under- or overestimate overall effects of

363 selection on the response of plants to different biotic conditions. We used five focal species

364 and observed strong differences regarding their selection response to community diversity. 


\subsection{Influence of plant selection history on biodiversity effects}

Net biodiversity effects can be partitioned into CEs and SEs. When CEs drive overyielding, most species contribute similarly to greater community productivity in mixtures, presumably due to niche differentiation among them. Conversely, SEs are large when few dominant species are driving positive diversity-productivity relationships, because they benefit from growing in mixtures (Loreau and Hector 2001).

Naïve plants exhibited weak biodiversity effects, confirming findings from a field experiment, where biodiversity effects were weaker for assemblages of naïve plants, especially at low diversity levels (van Moorsel et al., 2017). Such naïve plants, in contrast to plants with a common selection history, did not experience continued selection in field plots without re-sowing and did not previously experience interspecific competition. In contrast to our expectations, not only NEs and SEs but also CEs were larger for monoculture- than for mixture-type plant communities at the first harvest. However, the lower CEs of mixture-type communities could be attributed to a higher performance of mixture-type plants in monoculture assemblages and not to a lower performance in mixed assemblages. At second harvest, NEs, CEs and SEs were similar for mixture- and monoculture-type communities. Nevertheless, at least in four 2-species combinations $-L$. pratensis $+V$. chamaedrys, $G$. mollugo $+V$. chamaedrys, $V$. chamaedrys $+P$. vulgaris and $P$. lanceolata $+P$. vulgaris the directionality changed, i.e. CEs at the second harvest were larger for mixture- than for monoculture-type communities. Over longer timespans, CEs often increase and SEs often decrease (Fargione et al., 2007; Isbell et al., 2009; Marquard et al., 2009; Montès et al., 2008; van Ruijven and Berendse, 2005). Possibly this would have occurred in our experiment if we had continued beyond the 24-weeks of the study. 


\subsection{Influence of plant selection history on trait variation}

Because community-level trait variation can reflect niche differentiation (Roscher et al., 2015; Violle et al., 2012), we measured intra- and interspecific trait variation among individual plants in all assemblages. We expected larger interspecific trait variation for mixture-type plants undergoing possible selection for increased complementarity during twelve years in the experimental field plots. Conversely, we expected stronger within-species trait variation in monoculture-type plants with twelve years of strong intraspecific competition in the experimental field plots. However, monoculture-type plants tended to show higher intra and inter-specific trait variation (see Fig. 3). The relative extent of intraspecific trait variation may depend on species richness (Hulshof et al., 2013; Lamanna et al., 2014; Le Bagousse-Pinguet et al., 2014; Siefert et al., 2015) and in monocultures a large intraspecific variation is advantageous for a more efficient use of resources. Thus, the trend for increased trait variation in monoculture-type plants is consistent with potential selection for intraspecific niche widening by within-species character displacement during prolonged growth in monocultures.

However, less interspecific trait variation in mixture- compared with monoculturetype plants was in accordance with the lower CEs for mixture-type plants. These findings contrast with an earlier study in which larger CEs were observed for mixture- than for monoculture type plants and where mixture-type plants showed increased interspecific trait variation (Zuppinger et al., 2014). This earlier study included more species that were functionally different from each other, namely grasses, legumes, small herbs and tall herbs, which could potentially explain the contrasting results. More similar species, such as those used in the present study, may not be able to further increase trait differences in such a short time frame (Allan et al., 2013). Such species may have evolved "parallel" character displacement in response to species of the other functional groups also present in the 
mixtures in which they were selected in the Jena Experiment.

\subsection{Influence of trait variation and community-weighted means on biodiversity effects}

Selection for niche differentiation (Zuppinger-Dingley et al., 2014) could explain the

trait variations in mixture-type plants. Nevertheless, we did test for such relationships positively correlated with SEs.

RDs in plant height were negatively rather than positively correlated with CEs and 
Functional diversity in SLA within a community should increase complementary light use (Roscher et al., 2011). Leaf thickness is inherently related to SLA (White and Montes-R,

443 2005) and might act similarly to SLA. Here, RDs in leaf thickness, but not RDs in SLA,

444 were positively correlated with all biodiversity effects, especially for mixture-type plants.

445 Trait plasticity in leaf thickness was therefore advantageous for species growing in mixtures.

446 However, SEs increased as much as CEs, contrary to our expectation that positive

447 correlations between trait differences may mainly involve CEs. Furthermore, CWMs of SLA

448 had a positive effect on SEs, but also a negative effect on CEs, adding up to a negative effect

449 on NEs, suggesting that a smaller leaf area per unit mass for species growing in mixtures has

450 a positive effect on productivity.

\section{Conclusions}

Here, we demonstrated that community diversity had the selective potential to alter

454 species performances, which may in part explain the strengthening of biodiversityecosystem functioning relationship observed in field experiments (e.g. Reich et al., 2012).

Selection in a biodiversity experiment increased community productivity in newly assembled

history. Moreover, previous selection in mixtures increased community productivity in newly assembled mixtures and monocultures compared with previous selection in monocultures. These findings imply that co-evolutionary processes occurred in the 12-year selection period in the experimental plots of the biodiversity experiment and involving at

463 communities have implications for conservation strategies. Thus, it may not be sufficient to 464 only conserve species in isolation but rather in communities or populations of species with 465 co-evolved interactions. 


\section{Acknowledgements}

We are grateful to T. Zwimpfer, M. Furler, D. Trujillo and D. Topalovic for technical

469 assistance and E. de Luca, N. Castro and M. Brezzi for help with data measurements. This

470 study was supported by the Swiss National Science Foundation (grants number 147092 and

471166457 to B. Schmid) and the University Research Priority Program Global Change and

472 Biodiversity of the University of Zurich. The Jena Experiment is supported by the German

473 Science Foundation (FOR 1451, SCHM 1628/5-2). S.J. van Moorsel, B. Schmid and D.

474 Zuppinger-Dingley conceived the study, S.J. van Moorsel and T. Hahl carried out the

475 experiment and S.J. van Moorsel, M.W. Schmid and B. Schmid analyzed the data. S.J. van

476 Moorsel and B. Schmid wrote the manuscript with all other authors contributing to revisions.

478 Supplementary data

479 Supplementary data associated with this article can be found in the online version. 
480

481

482

483

484

485

486

487

488

489

490

491

492

493

494

495

496

497

498

499

500

501

502

503

504

\section{References}

Aarssen, L.W., 1983. Ecological Combining Ability and Competitive Combining Ability in Plants: Toward a General Evolutionary Theory of Coexistence in Systems of Competition. Am. Nat. 122, 707-731.

Allan, E., Jenkins, T., Fergus, A.J., Roscher, C., Fischer, M., Petermann, J., Weisser, W.W., Schmid, B., 2013. Experimental plant communities develop phylogenetically overdispersed abundance distributions during assembly. Ecology 94, 465-477.

Allan, E., Weisser, W., Weigelt, A., Roscher, C., Fischer, M., Hillebrand, H., 2011. More diverse plant communities have higher functioning over time due to turnover in complementary dominant species. Proc. Natl. Acad. Sci. 108, 17034-17039.

Anderson, J.T., Willis, J.H., Mitchell-Olds, T., 2011. Evolutionary genetics of plant adaptation. Trends Genet. 27, 258-266.

Bossdorf, O., Richards, C.L., Pigliucci, M., 2008. Epigenetics for ecologists. Ecol. Lett. 11, $106-115$.

Cadotte, M.W., 2017. Functional traits explain ecosystem function through opposing mechanisms. Ecol. Lett. 20, 989-996.

Cadotte, M.W., Cavender-Bares, J., Tilman, D., Oakley, T.H., 2009. Using Phylogenetic, Functional and Trait Diversity to Understand Patterns of Plant Community Productivity. PLoS ONE 4, e5695.

Cardinale, B.J., Duffy, J.E., Gonzalez, A., Hooper, D.U., Perrings, C., Venail, P., Narwani, A., Mace, G.M., Tilman, D., Wardle, D.A., Kinzig, A.P., Daily, G.C., Loreau, M., Grace, J.B., Larigauderie, A., Srivastava, D.S., Naeem, S., 2012. Biodiversity loss and its impact on humanity. Nature 486, 59-67.

Cardinale, B.J., Wright, J.P., Cadotte, M.W., Carroll, I.T., Hector, A., Srivastava, D.S., Loreau, M., Weis, J.J., 2007. Impacts of plant diversity on biomass production 
505

506

507

508

509

510

511

512

513

514

515

516

517

518

519

520

521

522

523

524

525

526

527

528

529

increase through time because of species complementarity. Proc. Natl. Acad. Sci. 104, 18123-18128.

Coley, P.D., Bryant, John P., Chapin, F. Stuart, 1985. Resource availability and plant antiherbivore defense. Science 230, 895-899.

Fakheran, S., Paul-Victor, C., Heichinger, C., Schmid, B., Grossniklaus, U., Turnbull, L.A., 2010. Adaptation and extinction in experimentally fragmented landscapes. Proc. Natl. Acad. Sci. 107, 19120-19125.

Fargione, J., Tilman, D., Dybzinski, R., Lambers, J.H.R., Clark, C., Harpole, W.S., Knops, J.M.., Reich, P.B., Loreau, M., 2007. From selection to complementarity: shifts in the causes of biodiversity-productivity relationships in a long-term biodiversity experiment. Proc. R. Soc. B Biol. Sci. 274, 871-876.

Flynn, D.F., Mirotchnick, N., Jain, M., Palmer, M.I., Naeem, S., 2011. Functional and phylogenetic diversity as predictors of biodiversity-ecosystem-function relationships. Ecology 92, 1573-1581.

Fornara, D.A., Tilman, D., 2008. Plant functional composition influences rates of soil carbon and nitrogen accumulation. J. Ecol. 96, 314-322.

Harper, J.L., 1977. Population biology of plants. London: Academic Press.

Hart, S.P., Schreiber, S.J., Levine, J.M., 2016. How variation between individuals affects species coexistence. Ecol. Lett. 19, 825-838.

Herms, D.A., Mattson, W.J., 1992. The Dilemma of Plants: To Grow or Defend. Q. Rev. Biol. 67, 283-335.

Hulshof, C.M., Violle, C., Spasojevic, M.J., McGill, B., Damschen, E., Harrison, S., Enquist, B.J., 2013. Intra-specific and inter-specific variation in specific leaf area reveal the importance of abiotic and biotic drivers of species diversity across elevation and latitude. J. Veg. Sci. 24, 921-931. 
530 Isbell, F., Calcagno, V., Hector, A., Connolly, J., Harpole, W.S., Reich, P.B., Scherer-

531

532

533

534

535

536

537

538

539

540

541

542

543

544

545

546

547

548

549

550

551

552

553

554

Lorenzen, M., Schmid, B., Tilman, D., van Ruijven, J., Weigelt, A., Wilsey, B.J., Zavaleta, E.S., Loreau, M., 2011. High plant diversity is needed to maintain ecosystem services. Nature 477, 199-202.

Isbell, F.I., Polley, H.W., Wilsey, B.J., 2009. Species interaction mechanisms maintain grassland plant species diversity. Ecology 90, 1821-1830.

Joshi, J., Schmid, B., Caldeira, M.C., Dimitrakopoulos, P.G., Good, J., Harris, R., Hector, A., Huss-Danell, K., Jumpponen, A., Minns, A., others, 2001. Local adaptation enhances performance of common plant species. Ecol. Lett. 4, 536-544.

Kleynhans, E.J., Otto, S.P., Reich, P.B., Vellend, M., 2016. Adaptation to elevated CO2 in different biodiversity contexts. Nat. Commun. 7, 12358.

Kraft, N.J.B., Godoy, O., Levine, J.M., 2015. Plant functional traits and the multidimensional nature of species coexistence. Proc. Natl. Acad. Sci. 112, 797-802.

Laliberté, E., Legendre, P., 2010. A distance-based framework for measuring functional diversity from multiple traits. Ecology 91, 299-305.

Laliberté, E., Legendre, P., Shipley, B., 2014. FD: measuring functional diversity from multiple traits, and other tools for functional ecology. R package version 1.0-12.

Lamanna, C., Blonder, B., Violle, C., Kraft, N.J.B., Sandel, B., imova, I., Donoghue, J.C., Svenning, J.-C., McGill, B.J., Boyle, B., Buzzard, V., Dolins, S., Jorgensen, P.M., Marcuse-Kubitza, A., Morueta-Holme, N., Peet, R.K., Piel, W.H., Regetz, J., Schildhauer, M., Spencer, N., Thiers, B., Wiser, S.K., Enquist, B.J., 2014. Functional trait space and the latitudinal diversity gradient. Proc. Natl. Acad. Sci. 111, 1374513750.

Le Bagousse-Pinguet, Y., Xiao, S., Brooker, R.W., Gross, N., Liancourt, P., Straile, D., Michalet, R., 2014. Facilitation displaces hotspots of diversity and allows 
communities to persist in heavily stressed and disturbed environments. J. Veg. Sci.

556 $25,66-76$.

557 Lipowsky, A., Schmid, B., Roscher, C., 2011. Selection for monoculture and mixture genotypes in a biodiversity experiment. Basic Appl. Ecol. 12, 360-371.

Loreau, M., Hector, A., 2001. Partitioning selection and complementarity in biodiversity experiments. Nature $72-76$.

561

562

563

564

565

566

567

568

569

570

571

572

573

574

575

576

577

578

Marquard, E., Weigelt, A., Roscher, C., Gubsch, M., Lipowsky, A., Schmid, B., 2009. Positive biodiversity-productivity relationship due to increased plant density. J. Ecol. 97, 696-704.

Montès, N., Maestre, F.T., Ballini, C., Baldy, V., Gauquelin, T., Planquette, M., Greff, S., Dupouyet, S., Perret, J.-B., 2008. On the Relative Importance of the Effects of Selection and Complementarity as Drivers of Diversity-Productivity Relationships in Mediterranean Shrublands. Oikos 117, 1345-1350.

Mueller, K.E., Tilman, D., Fornara, D.A., Hobbie, S.E., 2013. Root depth distribution and the diversity-productivity relationship in a long-term grassland experiment. Ecology 94, 787-793.

Niklaus, P.A., Baruffol, M., He, J.-S., Ma, K., Schmid, B., 2017. Can niche plasticity promote biodiversity-productivity relationships through increased complementarity? Ecology.

Price, T.D., Qvarnstrom, A., Irwin, D.E., 2003. The role of phenotypic plasticity in driving genetic evolution. Proc. R. Soc. B Biol. Sci. 270, 1433-1440.

Reich, P.B., Tilman, D., Isbell, F., Mueller, K., Hobbie, S.E., Flynn, D.F.B., Eisenhauer, N., 2012. Impacts of biodiversity loss escalate through time as redundancy fades. Science $336,589-592$ 
579 Roscher, C., Kutsch, W.L., Schulze, E.-D., 2011. Light and nitrogen competition limit

$580 \quad$ Lolium perenne in experimental grasslands of increasing plant diversity. Plant Biol.

$581 \quad 13,134-144$.

582 Roscher, C., Schumacher, J., Baade, J., Wilcke, W., Gleixner, G., Weisser, W.W., Schmid,

583 B., Schulze, E.-D., 2004. The role of biodiversity for element cycling and trophic

584 interactions: an experimental approach in a grassland community. Basic Appl. Ecol.

$585 \quad 5,107-121$.

586 Roscher, C., Schumacher, J., Gubsch, M., Lipowsky, A., Weigelt, A., Buchmann, N., Diversity-Productivity Relationships. PLoS ONE 7, e36760.

589 Roscher, C., Schumacher, J., Schmid, B., Schulze, E.-D., 2015. Contrasting effects of intraspecific trait variation on trait-based niches and performance of legumes in plant mixtures. PloS One 10, e0119786.

593

Roscher, C., Thein, S., Schmid, B., Scherer-Lorenzen, M., 2008. Complementary nitrogen use among potentially dominant species in a biodiversity experiment varies between two years. J. Ecol. 96, 477-488.

595 Rottstock, T., Kummer, V., Fischer, M., Joshi, J., 2017. Rapid transgenerational effects in Knautia arvensis in response to plant community diversity. J. Ecol. 105, 714-725.

597 Roughgarden, J., 1974. Niche width: biogeographic patterns among Anolis lizard populations. Am. Nat. 108, 429-442.

599 Schmid, B., 1985. Clonal Growth in Grassland Perennials: III. Genetic Variation and 600 Plasticity Between and Within Populations of Bellis Perennis and Prunella Vulgaris.

601 J. Ecol. 73, 819-830. 
602

603

604

605

606

607

608

609

610

611

612

613

614

615

616

617

618

619

620

621

622

623

624

625

Schnitzer, S.A., Klironomos, J.N., HilleRisLambers, J., Kinkel, L.L., Reich, P.B., Xiao, K., Rillig, M.C., Sikes, B.A., Callaway, R.M., Mangan, S.A., others, 2011. Soil microbes drive the classic plant diversity-productivity pattern. Ecology 92, 296-303.

Schoener, T.W., Gorman, G.C., 1968. Some niche differences in three lesser antillean lizards of the genos Anolis. Ecology 49, 819-830.

Siefert, A., et al., 2015. A global meta-analysis of the relative extent of intraspecific trait variation in plant communities. Ecol. Lett. 18, 1406-1419.

Soliveres, S. et al., 2016. Biodiversity at multiple trophic levels is needed for ecosystem multifunctionality. Nature 536, 456-459.

Spehn, E.M., Joshi, J., Schmid, B., Diemer, M., Korner, C., 2000. Above-Ground Resource Use Increases with Plant Species Richness in Experimental Grassland Ecosystems. Funct. Ecol. 14, 326-337.

Sterck, F., Markesteijn, L., Schieving, F., Poorter, L., 2011. Functional traits determine trade-offs and niches in a tropical forest community. Proc. Natl. Acad. Sci. 108, $20627-20632$.

Thorpe, A.S., Aschehoug, E.T., Atwater, D.Z., Callaway, R.M., 2011. Plant interactions and evolution. J. Ecol. 99, 729-740.

Tilman, D., Reich, P.B., Knops, J., Wedin, D., Mielke, T., Lehman, C., 2001. Diversity and productivity in a long-term grassland experiment. Science 294, 843-845.

Turcotte, M.M., Levine, J.M., 2016. Phenotypic Plasticity and Species Coexistence. Trends Ecol. Evol. 31, 808-813.

van Ruijven, J., Berendse, F., 2005. Diversity-productivity relationships: initial effects, longterm patterns, and underlying mechanisms. Proc. Natl. Acad. Sci. U. S. A. 102, 695700. 
626

627

628

629

630

631

632

633

634

635

636

637

638

639

640

641

642

643

644

645

646

647

648

van Valen, L., 1965. Morphological variation and width of ecological niche. Am. Nat. 99, $377-390$.

van Moorsel, S. J., Hahl, T., Wagg, C., De Deyn, G. B., Flynn, D.F.B., Zuppinger-Dingley, D., Schmid, B., 2017. Community evolution increases plant productivity at low diversity. bioRxiv 111617.

Vermeulen, P.J., Anten, N.P.R., Schieving, F., Werger, M.J.A., During, H.J., 2008. Height convergence in response to neighbour growth: genotypic differences in the stoloniferous plant Potentilla reptans. New Phytol. 177, 688-697.

Violle, C., Enquist, B.J., McGill, B.J., Jiang, L., Albert, C.H., Hulshof, C., Jung, V., Messier, J., 2012. The return of the variance: intraspecific variability in community ecology. Trends Ecol. Evol. 27, 244-252.

Violle, C., Navas, M.-L., Vile, D., Kazakou, E., Fortunel, C., Hummel, I., Garnier, E., 2007. Let the concept of trait be functional! Oikos 116, 882-892.

von Felten, S., Hector, A., Buchmann, N., Niklaus, P.A., Schmid, B., Scherer-Lorenzen, M., 2009. Belowground nitrogen partitioning in experimental grassland plant communities of varying species richness. Ecology 90, 1389-1399.

Wacker, L., Baudois, O., Eichenberger-Glinz, S., Schmid, B., 2009. Effects of plant species richness on stand structure and productivity. J. Plant Ecol. 2, 95-106.

White, J.W., Montes-R, C., 2005. Variation in parameters related to leaf thickness in common bean (Phaseolus vulgaris L.). Field Crops Res. 91, 7-21.

Williams, L.J., Paquette, A., Cavender-Bares, J., Messier, C., Reich, P.B., 2017. Spatial complementarity in tree crowns explains overyielding in species mixtures. Nat. Ecol. Evol. 1, 63. 
bioRxiv preprint doi: https://doi.org/101101/158709; this version posted October 3, 2017. The copyright holder for this preprint (which was not certified by peer review) is the author/funder, who has granted bioRxiv a license to display the preprint in perpetuity. It is made available under aCC-BY-NC-ND 4.0 International license. 


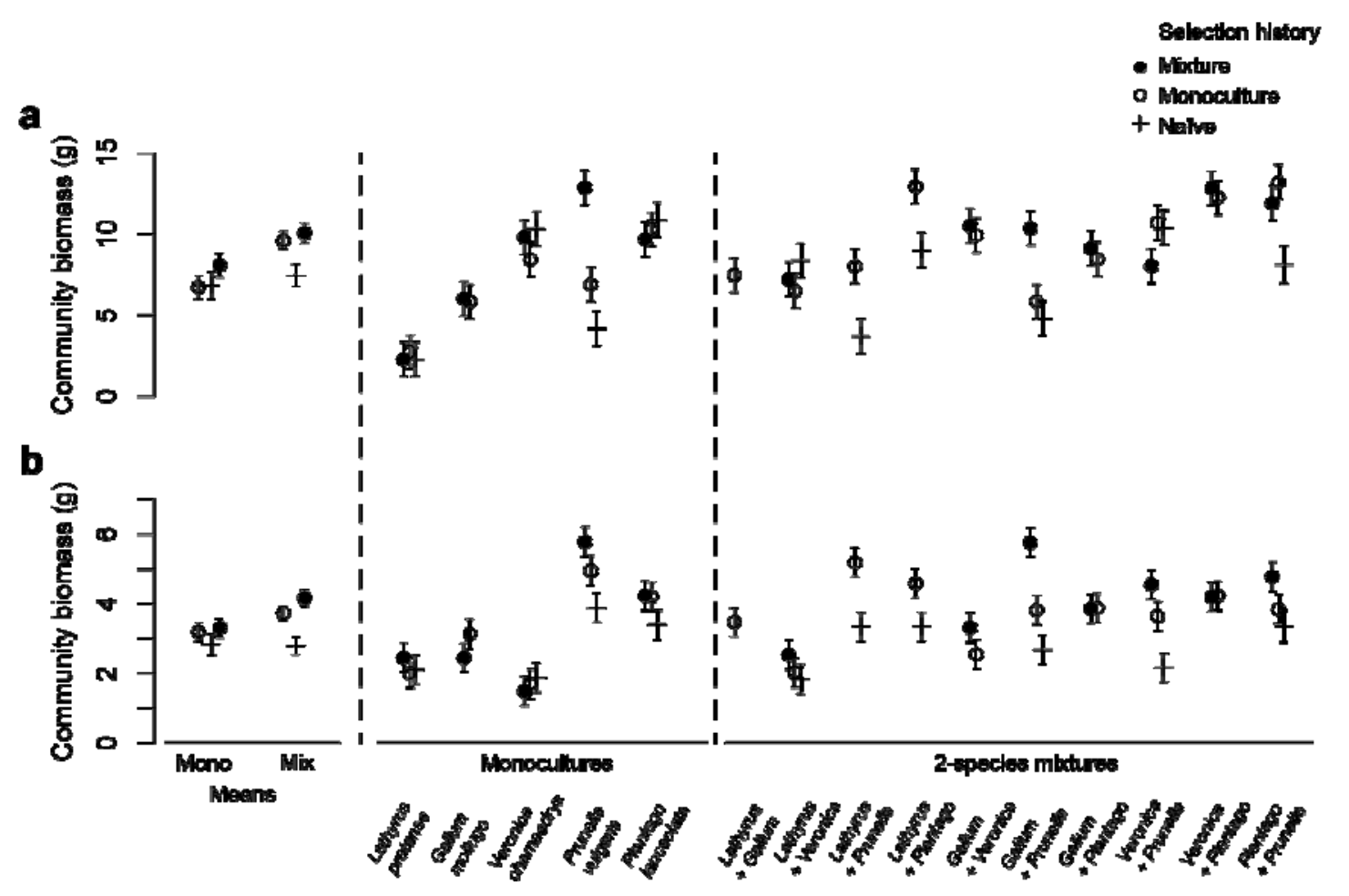

654 Fig. 1. Mean community biomass for monocultures and 2-species mixtures. Shown are

655 means and standard errors from a linear mixed-effects model with selection history, species

656 combination and the interaction between selection history and species assembly as fixed-

657 effects terms and table (including the block) as random-effects term. a, first harvest. b, 658 second harvest. 


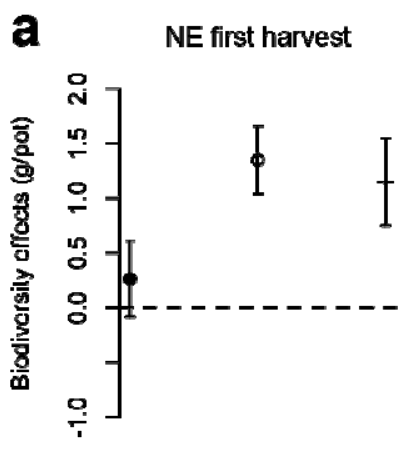

b

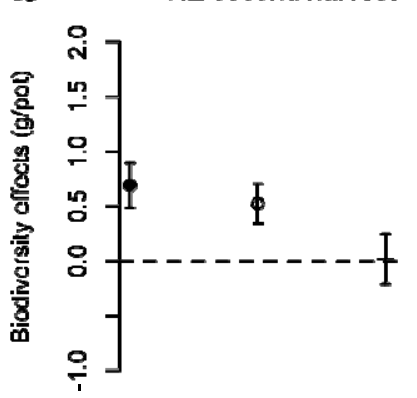

CE first harvest

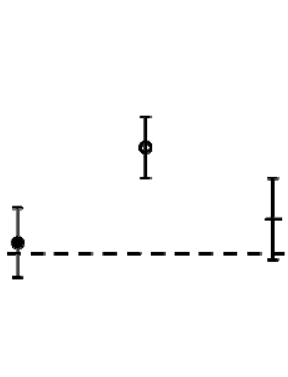

CE second harvest
Selection history

SE first harvest

- Mixture

- Monoculture

+ Naïve

Fig. 2. We assessed biodiversity effects for both biomass harvests by additive partitioning of

664 the net effect (a, NE) into complementarity effect (b, CE) and sampling effect (c, SE) for

665 plants with different selection histories (naïve, monoculture, mixture). Shown are means and

666 standard errors from a linear mixed-effects model, with selection history as fixed-effects

667 term and species assembly, the interaction between selection history and species assembly

668 and table (including block) as random-effects terms. 

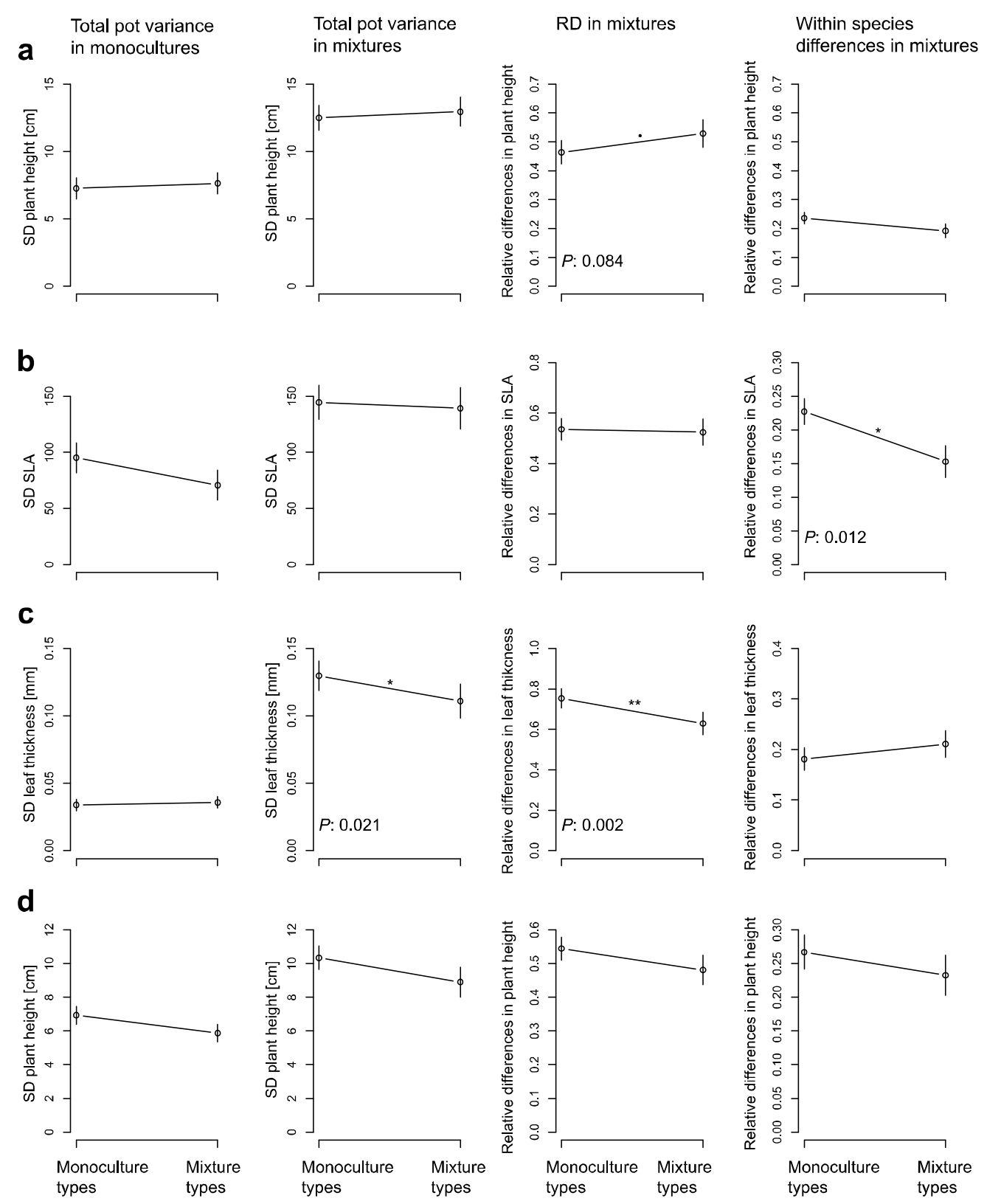

671 Fig. 3. Trait variance in monoculture and mixture assemblages in response to selection

672 history (monoculture- vs. mixture-type plants). a) plant height at first harvest, b) SLA at the

673 first harvest, $\mathbf{c})$ leaf thickness at the first harvest, d) plant height at second harvest. Shown

674 are means and standard errors from a mixed-effects model with selection history, species

675 assembly and the two-way interaction of these as fixed-effects terms and table (including block) as random term. Significant and marginally significant $P$-values are indicated in the 

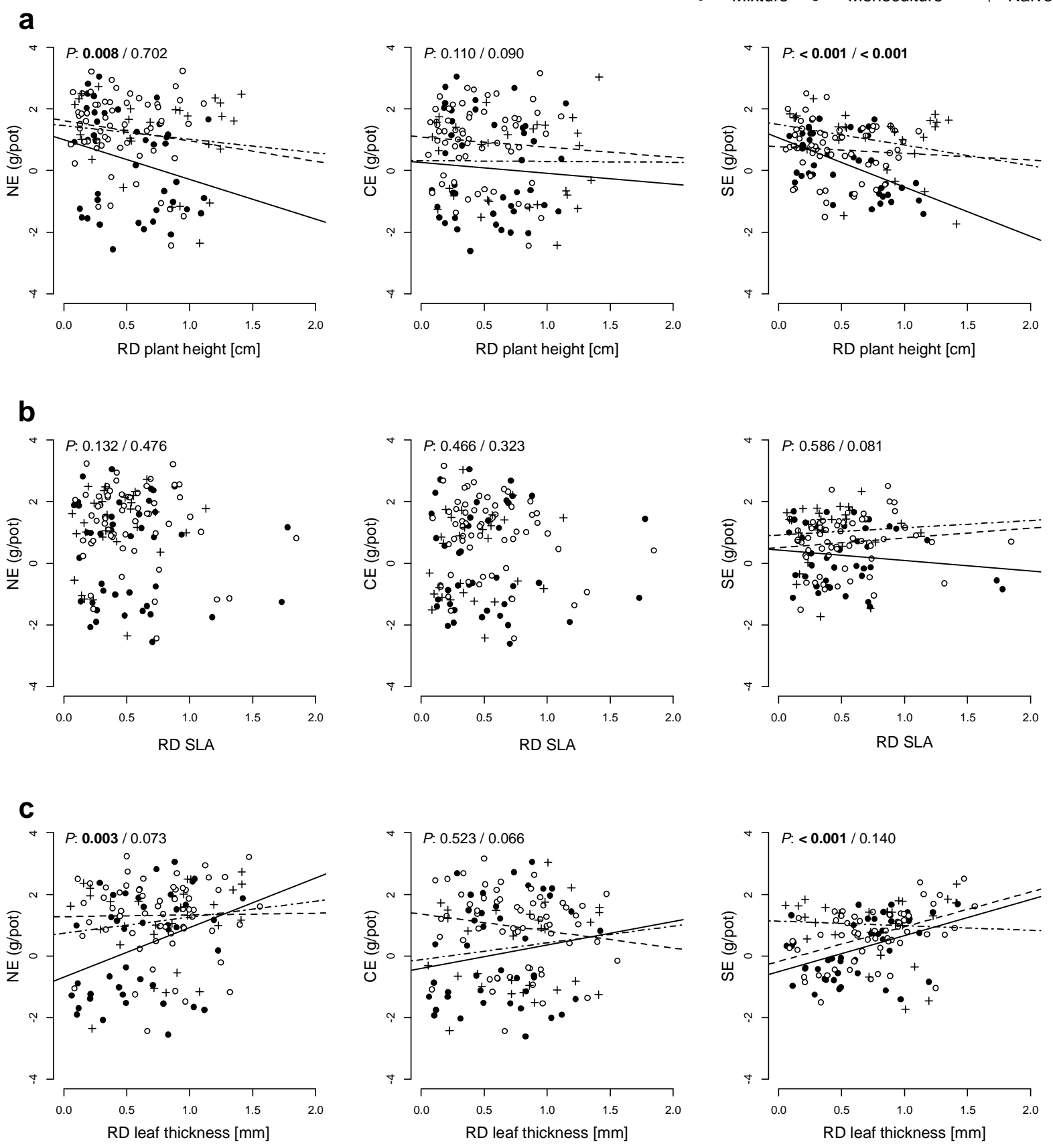

678

679 Fig. 4. Biodiversity effects at the first harvest in response to relative differences between

680 species (RDs) for three traits: a, plant height (in $\mathrm{cm}$ ), b, specific leaf area (SLA) and $\mathbf{c}$, leaf

681 thickness (in mm). Indicated $P$-values refer to ANOVA results for fixed-effects terms from a

682 mixed-effects model with RD, species assembly, selection history and interactions of these 
683 as fixed-effects terms and table (including block) as random-effects term: RD / interaction

684 RD $\times$ selection history (naïve plants vs. mixture types vs. monoculture types). Regression

685 lines are plotted in cases for which at least one $P$-value was significant. Left column: NE,

686 middle column: CE, right column: SE. 
688

689
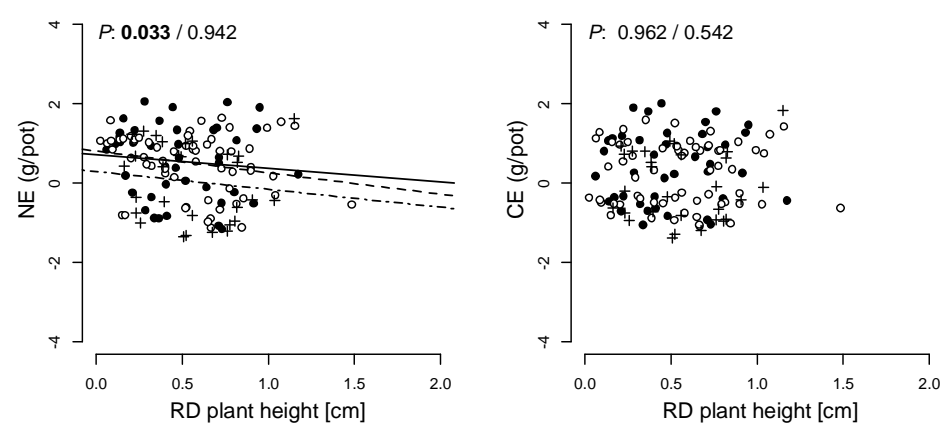

$\longrightarrow$ Mixture - o- - Monoculture -.--+ Naïve

690 Fig. 5. Biodiversity effects at the second harvest in response to relative differences between

691

species for plant height (in $\mathrm{cm}$ ). Indicated $P$-values refer to ANOVA results for fixed-effects

692

terms from a mixed-effects model with $\mathrm{RD}$, species assembly, selection history and

693 interactions of these as fixed-effects terms and table (including block) as random-effects

694 term: $\mathrm{RD} /$ interaction $\mathrm{RD} \times$ selection history (naïve plants vs. mixture types vs. monoculture

695 types). Regression lines are plotted in cases for which at least one $P$-value was significant.

696 Left column: NE, middle column: CE, right column: SE. 


\section{a}

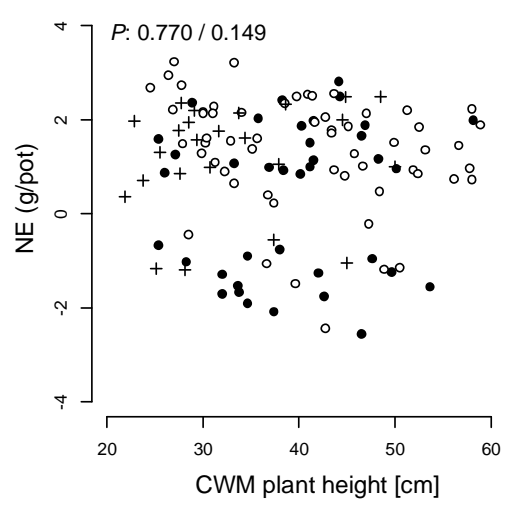

b
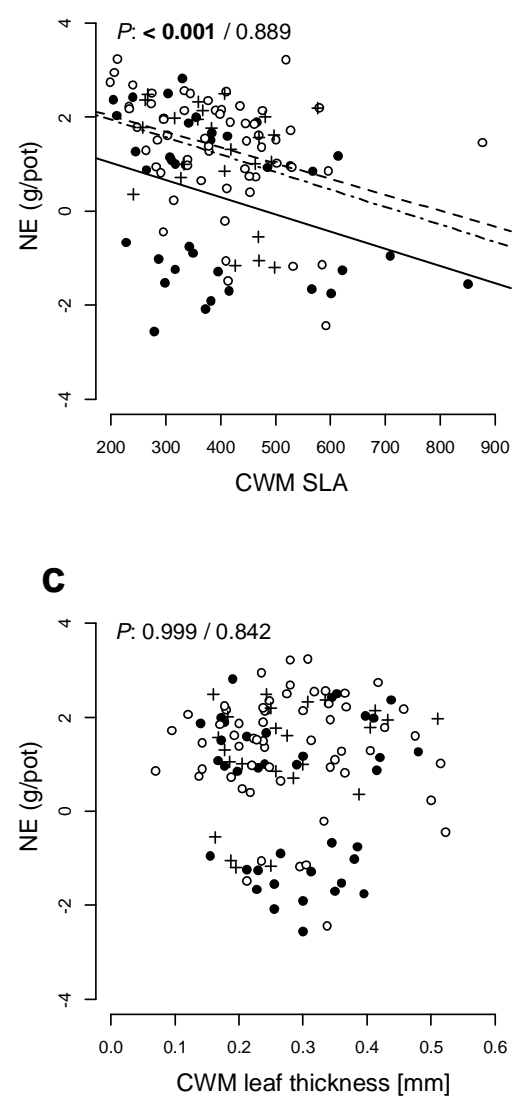
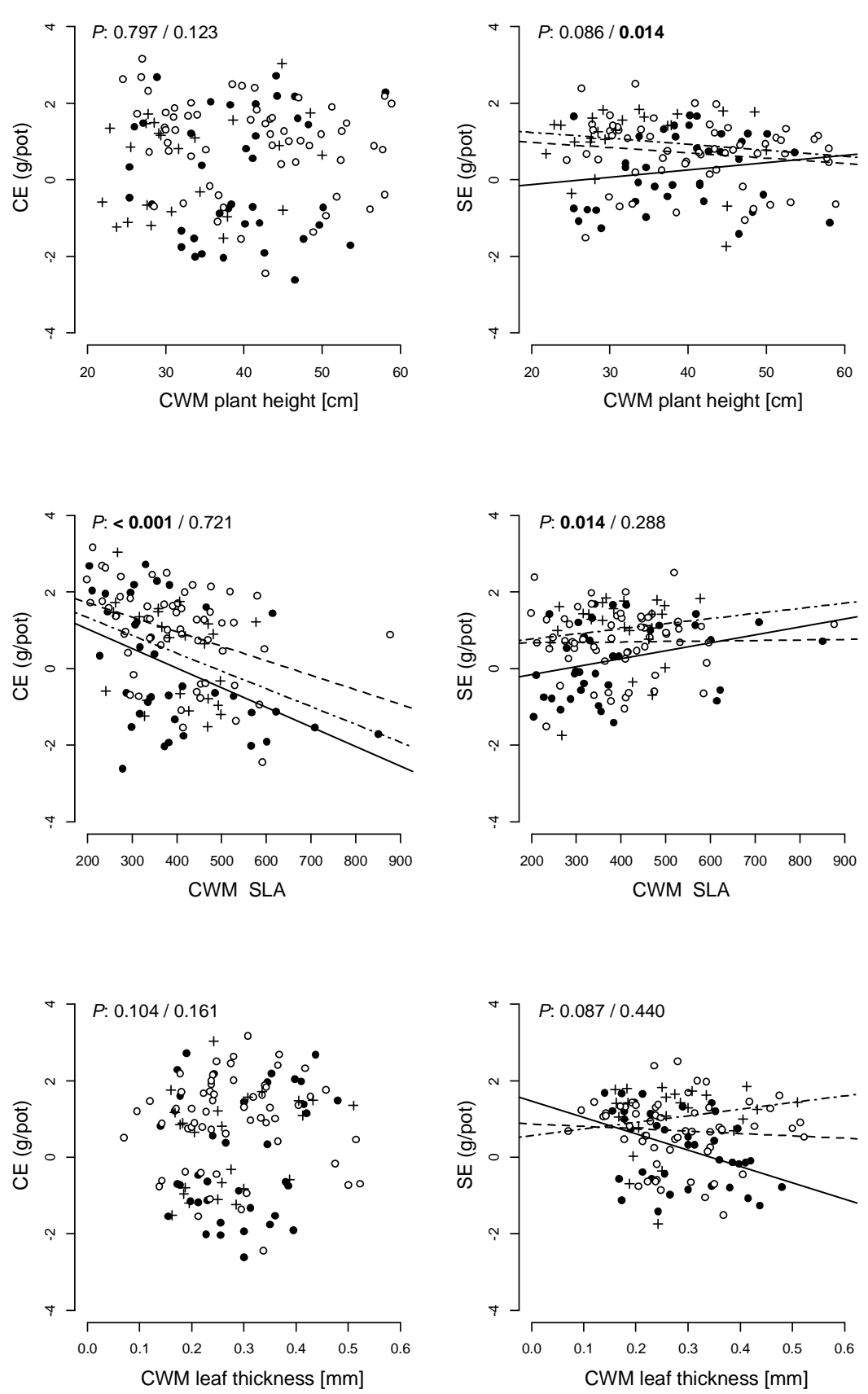

698

699

700

701

702

703

704

FIG. 6. Biodiversity effects at the first harvest in response to the community-weighted mean

$(\mathrm{CWM})$ of three traits: a, plant height (in $\mathrm{cm}), \mathbf{b}$, specific leaf area (SLA) and c, leaf

thickness (in mm). Indicated $P$-values refer to ANOVA results for fixed-effects terms from a

mixed-effects model with CWM, species assembly, selection history and interactions of these as fixed-effects terms and table (including block) as random-effects term: CWM / 
705 interaction $\mathrm{CWM} \times$ selection history (naïve plants vs. mixture types vs. monoculture types).

706 Regression lines are plotted in cases for which at least one $P$-value was significant. Left

707 column: NE, middle column: CE, right column: SE.

708 

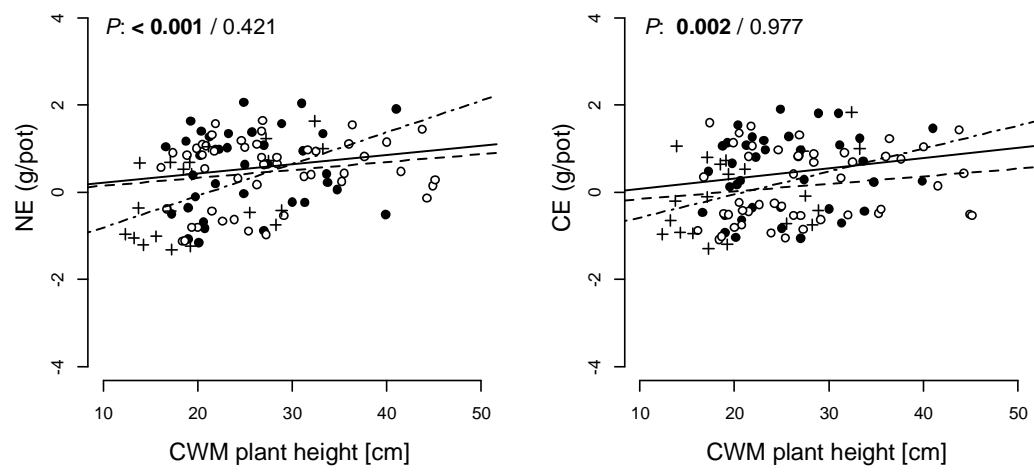

$\multimap$ Mixture - o-- Monoculture --·-+ - Naïve

Fig. 7. Biodiversity effects at the second harvest in response to the community-weighted mean $(\mathrm{CWM})$ of plant height (in $\mathrm{cm})$. Indicated $P$-values refer to ANOVA results for fixed-

effects terms from a mixed-effects model with CWM, species assembly, selection history and interactions of these as fixed-effects terms and table (including block) as random-effects term: $\mathrm{CWM} /$ interaction $\mathrm{CWM} \times$ selection history (naïve plants vs. mixture types vs. monoculture types). Regression lines are plotted in cases for which at least one $P$-value was significant. Left column: NE, middle column: CE, right column: SE. 
Table 1. Results of mixed-effects ANOVA for the aboveground biomass of the test assemblages at first harvest after 12 weeks of growth (a) and

719

\begin{tabular}{|c|c|c|c|c|c|c|c|c|}
\hline \multirow{2}{*}{ Source of variation } & & & \multicolumn{3}{|c|}{ a) Harvest 1} & \multicolumn{3}{|c|}{ b) Harvest 2} \\
\hline & & nDf & $\mathrm{dDF}$ & $F$ & $P$ & $\mathrm{dDF}$ & $F$ & $P$ \\
\hline \multicolumn{9}{|l|}{ Species assembly: } \\
\hline & Monoculture vs. mixture & 1 & 173.3 & 29.09 & $<0.001$ & 174 & 10.78 & 0.001 \\
\hline & $\begin{array}{l}\text { Monoculture identity or species combination of } \\
\text { mixture }\end{array}$ & 13 & 171.2 & 16.53 & $<0.001$ & 171.8 & 15.47 & $<0.001$ \\
\hline \multicolumn{9}{|c|}{ 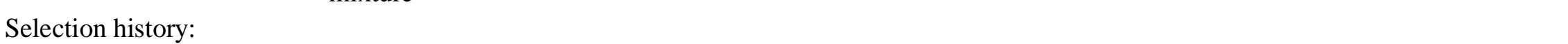 } \\
\hline & Naïve vs. mono or mix types & 1 & 173 & 16.63 & $<0.001$ & 173.7 & 42.72 & $<0.001$ \\
\hline & Mono vs. mix types & 1 & 169.6 & 1.78 & 0.184 & 170.1 & 5.71 & 0.018 \\
\hline \multicolumn{9}{|l|}{ Assembly $\times$ history: } \\
\hline & $\begin{array}{l}\text { Monoculture vs. mixture } \times \text { naïve vs. mono or mix } \\
\text { types }\end{array}$ & 1 & 168.4 & 1.72 & 0.191 & 168.8 & 8.56 & 0.004 \\
\hline & Monoculture vs. mixture $\times$ Mono or mix types & 1 & 172.2 & 1.69 & 0.195 & 172.9 & 3.52 & 0.062 \\
\hline \multicolumn{9}{|c|}{ Species assembly $\times$ history: } \\
\hline & Species assembly $\times$ naïve vs. mono or mix types & 8 & 171.7 & 5.35 & $<0.001$ & 172.3 & 2.15 & 0.033 \\
\hline & Species assembly $\times$ mono types vs. mix types & 10 & 172.3 & 2.91 & 0.002 & 172.9 & 1.23 & 0.275 \\
\hline
\end{tabular}

$\mathrm{nDF}=$ numerator degrees of freedom, $\mathrm{dDF}=$ denominator degrees of freedom, $F=$ variance ratio, $P=$ probability of type-I error. $\mathrm{Variance}$ components (Var) and associated standard errors (SE) for the random effects are provided together with the number of replicates. 
722 Table 2. Results of mixed-effects ANOVA for biodiversity effects of the test assemblages at

723 the first harvest after 12 weeks of growth (a) and at the second harvest after 24 weeks of

724 growth (b).

a) NE Harvest 1

\begin{tabular}{lccccccc}
\hline Source of variation & $\mathrm{nDf}$ & $\mathrm{dDF}$ & $F$ & $P$ & $\mathrm{dDF}$ & $F$ & $P$ \\
\hline Overall mean & 1 & 15.9 & 26.67 & $<0.001$ & 15.1 & 14.35 & 0.002 \\
Naïve vs. mono or mix types & 1 & 95.3 & 0.806 & 0.372 & 96.1 & 11.54 & $<0.001$ \\
Mono types vs. mix types & 1 & 93.9 & 21.01 & $<0.001$ & 93.6 & 0.026 & 0.872 \\
Species assembly & 9 & 96.7 & 2.646 & 0.009 & 97.7 & 4.837 & $<0.001$ \\
Species assembly $\times$ naïve vs. mono or mix types & 4 & 97.5 & 4.459 & 0.002 & 98.9 & 1.463 & 0.219 \\
Species assembly $\times$ mono types vs. mix types & 6 & 98 & 4.095 & 0.001 & 99 & 1.518 & 0.18
\end{tabular}

a) CE harvest 1

\begin{tabular}{lccccccc}
\hline Source of variation & $\mathrm{nDf}$ & $\mathrm{dDF}$ & $F$ & $P$ & $\mathrm{dDF}$ & $F$ & $P$ \\
\hline Overall mean & 1 & 15.8 & 8.214 & 0.011 & 14.5 & 4.108 & 0.061 \\
Naïve vs. mono or mix types & 1 & 95.9 & 1.427 & 0.235 & 96.6 & 5.668 & 0.019 \\
Mono types vs. mix types & 1 & 94.4 & 14.2 & $<0.001$ & 93.8 & 1.524 & 0.22 \\
Species assembly & 9 & 97.4 & 2.534 & 0.012 & 98.4 & 1.121 & 0.356 \\
Species assembly $\times$ naïve vs. mono or mix types & 4 & 98.3 & 1.835 & 0.128 & 99.7 & 0.584 & 0.675 \\
Species assembly $\times$ mono types vs. mix types & 6 & 98.8 & 2.53 & 0.025 & 99.8 & 0.468 & 0.831
\end{tabular}

a) SE harvest 1

b) SE Harvest 2

\begin{tabular}{lccccccc}
\hline Source of variation & $\mathrm{nDf}$ & $\mathrm{dDF}$ & $F$ & $P$ & $\mathrm{dDF}$ & $F$ & $P$ \\
\hline Overall mean & 1 & 14.2 & 97.07 & $<0.001$ & 15.1 & 11.66 & 0.004 \\
Nä̈ve vs. mono or mix types & 1 & 104.2 & 12.66 & 0.001 & 98.8 & 2.224 & 0.139 \\
Mono types vs. mix types & 1 & 101.2 & 10.28 & 0.002 & 95.7 & 2.37 & 0.127 \\
Species assembly & 9 & 105.5 & 5.793 & $<0.001$ & 100.8 & 11.53 & $<0.001$ \\
Species assembly $\times$ naïve vs. mono or mix types & 4 & 105.9 & 10.08 & $<0.001$ & 102 & 3.517 & 0.01 \\
Species assembly $\times$ mono types vs. mix types & 6 & 105.9 & 2.865 & 0.013 & 101.9 & 2.541 & 0.025 \\
\hline
\end{tabular}

$\mathrm{nDF}=$ numerator degrees of freedom, $\mathrm{dDF}=$ denominator degrees of freedom, $F=$ variance ratio, $P=$ probability of type-I error. Variance components (Var) and associated standard errors (SE) for the random effects are provided together with the number of replicates.

725

726 